\title{
Evolution of crystal orientation in snow during temperature gradient metamorphism
}

\author{
Fabienne RICHE, ${ }^{1}$ Maurine MONTAGNAT, ${ }^{2}$ Martin SCHNEEBELI ${ }^{1}$ \\ ${ }^{1}$ WSL Institute for Snow and Avalanche Research SLF, Davos Dorf, Switzerland \\ E-mail: schneebeli@slf.ch \\ ${ }^{2}$ Laboratoire de Glaciologie et Géophysique de I'Environnement, CNRS/Université Joseph Fourier - Grenoble I, \\ Grenoble, France
}

\begin{abstract}
The physical properties of snow are tied to its microstructure. Especially for the slow, plastic deformation of snow and firn, the crystal orientation is an important factor in addition to the geometry of the ice matrix. While micro-computed tomography measures the snow microstructure precisely, it gives no information about the orientation of the ice crystals. In this study, we applied a temperature gradient of $50 \mathrm{~K} \mathrm{~m}^{-1}$ to large blocks of undisturbed decomposed snow and sieved snow during 3 months. The mean temperature of the snow samples during the temperature gradient experiment was $-20^{\circ} \mathrm{C}$. Two closely spaced snow samples were taken before the experiment, then every week during the first month and afterwards every month. From each sampling, one sample was analyzed by micro-computed tomography and the other was used for thin sections. The orientation of the $c$-axis was measured in the thin sections using an automatic ice texture analyzer. Initial density was $30 \%$ higher in the sieved snow sample. Density and specific surface area evolved alike, while the fabric showed a different evolution between the two samples. The undisturbed snow evolved from a weak single-maximum fabric towards a weak girdle fabric, while the sieved sample showed no evolution. The undisturbed snow sample converged toward the sieved sample fabric after 6 weeks, but continued its evolution thereafter. We suggest that the main factor causing this different behavior is the difference in density and in pore size.
\end{abstract}

\section{INTRODUCTION}

Snow crystals are crystallographically anisotropic, as expressed in their immensely variable shape (Nelson, 2001). Plate-like crystals are short in the $c$-axis direction, while columns and needles are long in the $c$-axis direction. If snow fell with a small range of shapes, each snowfall might create a layer where the texture, the arrangement and orientation of the crystals has a strong peak in orientation. (The definition of the terms texture, microstructure and fabric follows Durand and others (2006). Texture includes both microstructure and fabric: the microstructure is given by the outer geometry of the ice structures, and fabric refers to the orientation of the $c$-axes.) In fact, Magono and Suzuki (1967) showed that the $c$-axes of snow dendrites are close to perpendicular to the surface of the crystals. Takahashi and Fujino (1976) and De Quervain (1983) measured the fabric of a few snow samples, but the data are too few to draw firm conclusions. However, the texture of new snow on the ground has never been intensively studied, which leads to the question whether this potential anisotropy is formed and maintained during metamorphism. During temperature gradient metamorphism, the snow crystals (grains) completely recrystallize, and the newly formed grains can have a different grain size, shape and orientation (Pinzer and others, 2012). Time-lapse observations show a random growth and decay of snow grains, but no information about crystal orientation can be gained from these data (Pinzer and Schneebeli, 2009; Pinzer and others, 2012). Nevertheless, the preferential growth of the basal and prismatic face of the ice crystal is temperature-dependent (Kuroda and Lacmann, 1982), so it is straightforward to imagine that crystals with an initial orientation conducive to preferred growth become dominant. This is derived from qualitative observations in snow profiles, where cups grow preferentially downwards
(Sturm and Benson, 1997). Adams and Miller (2003) observed preferential growth of crystals from vapor onto an oriented substrate, and speculated on the effect of depth-hoar development in snow. From these experiments, the favored orientation growth will strongly depend on the temperature and level of supersaturation, and also on the available pore space in the preferred growth direction. However, the very few studies of crystal orientation in snow and superficial firn leave open the validity of these assumptions (Bader and others, 1939; Stephenson and Lister, 1959; Takahashi and Fujino, 1976).

Accurate knowledge of fabric anisotropy is crucial for the mechanical behavior of snow layers, but is also important for understanding metamorphism. Ice has a very strong visco-plastic anisotropy depending on the orientation of the shear plane (Duval and others, 1983). Snow with a fabric of preferred orientations will then densify differently (Theile and others, 2011). Indeed, the origin of non-isotropic fabrics measured in polar firn remains unclear, and needs to be better understood to constrain firn densification modeling (Durand and others, 2007; Hörhold and others, 2011; Montagnat and others, 2012).

The automatic ice-texture analyzer (AITA) developed by Wilson and others (2003) has enabled fast and precise measurement of the fabric of many small ice crystals. It is the first fully functional instrument to measure $c$-axis orientation in ice, and is based on many earlier attempts (Good, 1970; Heilbronner and Pauli, 1993) to improve the precision and speed of the Rigsby stage (Rigsby, 1951). The high spatial resolution provided by the AITA (close to $5 \mu \mathrm{m}$ ) makes it practical for snow.

X-ray microtomography $(\mu \mathrm{CT})$ is used to obtain threedimensional (3-D) images of snow samples and their structural parameters (Flin and others, 2004; Schneebeli 
and Sokratov, 2004; Kaempfer and others, 2005) and has become a standard to characterize the complete snow microstructure. Diffraction contrast tomography (Ludwig and others, 2009; Rolland du Roscoat and others, 2011) provides combined information on fabric and microstructure. However, this technique is not yet sufficiently developed to be applied to a large number of crystals, such as occurs in a natural snow sample.

The goal of our experiment was to analyze the microstructural change in the geometry combined with the evolution of the c-axis orientations and number of ice crystals during temperature gradient metamorphism of a snow sample. We used large blocks of naturally deposited and sieved snow. Most of the snow crystals were dendritic or platelets. The sieved snow was from the same snowfall as the undisturbed blocks. The blocks were metamorphosed under a temperature gradient of $50 \mathrm{~K} \mathrm{~m}^{-1}$ in the laboratory for $\sim 12$ weeks, purposely at the low temperature of $-20^{\circ} \mathrm{C}$, to be closer to the conditions of a polar snowpack. Based on the measurement of residence time, defined as the average time a snow grain exists, the experiment included about 11 generations, i.e. complete sublimation-deposition of a crystal (Pinzer and others, 2012). About every 2 weeks a snow sample was extracted and analyzed. The sample was used to make thin sections and microtomographic images.

The most obvious difference between the two samples, which persisted during the experiment, was in their density. The initial fabric also differed slightly between the two groups. We analyzed and interpreted the evolution of microstructure and fabric to determine the differences between these two samples.

\section{METHOD}

\section{Experiment}

A block of $30 \times 30 \times 30 \mathrm{~cm}^{3}$ of homogeneous natural dry snow was extracted from the snow cover at $2540 \mathrm{~m}$ altitude in Davos, Switzerland. The experiment was prepared in a large box $(50 \mathrm{~cm}$ wide, $100 \mathrm{~cm}$ long) with insulated walls and an electrically heated and temperature-controlled bottom plate. First, the bottom was covered with a $2 \mathrm{~mm}$ thick solid ice layer. Then the block was placed and cut to a height of $20 \mathrm{~cm}$. Around the block, the box was filled up to a height of $20 \mathrm{~cm}$ with sieved snow to allow homogeneous temperature conditions. The temperature at the bottom was set to $-15^{\circ} \mathrm{C}$, and the air temperature to $-25^{\circ} \mathrm{C}$, causing a temperature gradient of $50 \mathrm{~K} \mathrm{~m}^{-1}$ through the snowpack. Temperatures at the top and bottom of the block were measured with temperature sensors (iButton DS1921L, Maxim Integrated Products) with an accuracy of $\pm 0.5^{\circ} \mathrm{C}$.

A first sample was extracted from the natural snow block (Group 1) before being submitted to the temperature gradient. Afterwards, five samples were extracted after 1, 2, 4, 6 and 12.5 weeks. The samples were always cut out $10 \mathrm{~cm}$ below the top of the block. The same procedure was used for samples of sieved snow (Group 2), with a total of five samples after $0,1,4,6$ and 11.5 weeks (the last sample was collected 1 week earlier than the last Group 1 sample). The same snow as in Group 1 was used for sieving. The initial snow of Group 1 was classified as partly decomposed precipitation particles, and the initial snow of Group 2 as wind-broken precipitation particles (Fierz and others, 2009). The initial structural properties of the two groups at $t=0$ week are shown in Figure 2.
Once extracted, the samples were scanned with the $\mu \mathrm{CT}$ to measure the geometrical properties of the microstructure and afterwards filled with diethyl phthalate (CAS 84-66-2) to make thin sections and analyze the $c$-axis orientations (fabric) with the AITA.

\section{X-ray tomography and microstructural parameters}

The technique used in the present study has been described elsewhere (Kaempfer and others, 2005; Riche and Schneebeli, 2010). We therefore summarize the main characteristics briefly. The $10.8 \mathrm{~mm}$ height of each sample was scanned in a $36 \mathrm{~mm}$ diameter probe in a micro-CT 80 (Scanco Medical). The 3-D image resolution was $18 \mu \mathrm{m}$. Image Processing Language (IPL) was used to segment the $3-\mathrm{D}$ images. A block of $600^{3}$ voxels $\left(10.8^{3} \mathrm{~mm}^{3}\right)$ was extracted at a fixed position of the $\mu \mathrm{CT}$ measurement. A Gaussian filter was used on this volume (sigma $=1$, support $=2$ ), then an adaptive threshold was applied to segment the image between air and ice. Grain thickness Th, pore size Sp, volume density and SSA were evaluated from the 3-D image, using a surface triangulation method implemented in IPL (Hildebrand and Rüegsegger, 1997; Hildebrand and others, 1999). To calculate the degree of anisotropy of the structure (DA-S), the orientation and area of the triangles were calculated (Hildebrand and others, 1999). A polar histogram with $30^{\circ}$ bins was calculated based on the area and orientation of the triangles. A second-order tensor was calculated from the histogram. DA$S$ is then the ratio between the major and minor eigenvalues. The structure is isotropic when DA-S $=1$ (Thorsteinsson and others, 1997; Hildebrand and others, 1999; Schneebeli and Sokratov, 2004).

\section{Thin sectioning and fabric measurements}

Thin sections were cut out of the impregnated samples to a thickness of 120-150 $\mu \mathrm{m}$ as described by Riche and others (2012). Once prepared, the thin sections were analyzed with the AITA. The AITA is an automated polarizing optical microscope G50 (Russell-Head Instruments) that determines the orientation of the $c$-axes of uniaxial crystals at each pixel in the field of view (Wilson and others, 2003, 2007). The analyzer provides a spatial resolution of $6.5 \mu \mathrm{m}$ per pixel and an angular resolution for the $C$-axis orientation of $\sim 3^{\circ}$ (Peternell and others, 2009). The impregnated thin section consists of ice crystals surrounded by diethyl phthalate (DEP). Crystallized DEP is birefringent and disturbs the observation of ice crystals under polarized light. To liquefy the DEP, a few drops of tetraline (solvent for DEP) were added at the edge of the section. We verified that this operation caused only very slight rotation or translation of a few of the smallest snow crystals. These rotations would induce errors below the range of accuracy of the AITA. Three horizontal thin sections were randomly cut out of each sample, and a total of 100-300 grains per sample were analyzed. For each pixel, the analyzer provides the orientation of the $c$-axis, relative to the thin section (horizontal plane), in spherical coordinates: the azimuth $\theta$ (angle in the horizontal plane, $0-360^{\circ}$ ) and the co-latitude $\varphi$ (angle in the vertical plane, $0-180^{\circ}$ ). Based on azimuth and co-latitude, a colored image is produced (Peternell and others, 2009). Hue indicates the azimuth. Decreasing brightness stands for decreasing co-latitude (black stands for a vertical $c$-axis). For each pixel, a quality factor $(0-100 \%)$ is provided, which depends on how well the orientation could be determined. The raw data serve to produce eigenvalues of the 
orientations and to calculate the Schmidt plot, a stereographic projection of the $c$-axes. The number of crystals in a volume can be estimated by the Rhines-DeHoff relation $N_{A}=E_{N}[H] \cdot N_{V}$, where $N_{A}$ is the number of counted crystals in the section, $E_{N}[H]$ the mean particle height, corresponding to the thickness Th, and $N_{V}$ is the number of particles per unit volume (Baddeley and Vedel Jensen, 2005, section 11.1.1).

The number of crystals was counted on a slice within the reference area of $8.4 \times 8.4 \mathrm{~mm}^{2}$ (Fig. 3). Close observation of the images showed that complex shapes of new snow, as capped columns, were split into several blobs of the same color. This also occurred for depth-hoar crystals. We counted such neighboring blobs of the same color with identical orientation as a single crystal. By combining the thickness of ice structures from $\mu \mathrm{CT}$ with the counting of crystals on the thin section, we estimate that the error in the number of crystals is $<10 \%$. We are aware that this method of counting may not be unbiased. However, the dissector technique (Baddeley and Vedel Jensen, 2005) was impossible to apply, as we cannot produce consecutive thin sections.

\section{Processing of the fabric measurements}

The raw data produced by the AITA were analyzed using a MATLAB toolbox based on Durand and others (2006). This toolbox, originally designed for thin sections of solid polycrystalline ice, had to be adapted to snow samples. To this end, a new filter was added to the toolbox to suppress air pores. In a first step, the 'black' (in reality transparent and not birefringent) DEP pixels are removed by thresholding. In a second step, an opening operation is performed, which removes spurious pixels at the interface between the ice crystals and the liquid DEP. In a second step, the data are filtered following Peternell and others (2009), and all pixels with a quality factor lower than $70 \%$ are removed. Pixels with co-latitude and azimuth equal to zero were considered as artifacts and eliminated.

Spherical data, as produced for the $c$-axis orientation data, are commonly analyzed by a transformation to a second-order orientation tensor (Fisher, 1993). The tensor $\mathbf{a}^{(2)}$ is given by

$$
\mathbf{a}^{(2)}=\left(1 / N_{\mathrm{p}}\right) \sum_{k=1}^{N_{\mathrm{p}}} c^{k} \otimes c^{k},
$$

where $c^{k}$ is the crystal orientation of one measured pixel of the thin section, given in spherical coordinates, $\otimes$ is the tensor product and $N_{p}$ is the number of measured pixels in the thin section. Since the $c^{k}$ values are obtained at pixel size, the definition of $\mathbf{a}^{(2)}$ given by Eqn (1) implicitly takes into account the volume fraction of grains. The eigenvectors of $\mathbf{a}^{(\mathbf{2})}$ give the axis directions of the ellipsoid containing the orientation distribution. The eigenvalues, $a_{1,2,3}$, (with $1>a_{1}>a_{2}>a_{3}>0$ and $a_{1}+a_{2}+a_{3}=1$ ) give the length of the three principal axes (the eigenvectors) of this ellipsoid. By definition, when the fabric is isotropic, the three eigenvalues are equal to $1 / 3$. A single-maximum fabric is given when the majority of the $c$-axes of the crystals are vertical, and a girdle fabric is where the $c$-axes are randomly oriented in the horizontal plane (in our case the plane of the thin section). When two eigenvalues are close and smaller than $1 / 3$, the fabric is a single-maximum fabric, and when two eigenvalues are close and larger than $1 / 3$, the fabric is characterized by a girdle. A supplementary visualization tool which reveals the evolution and strength of the fabric is based on Fisher (1993). Here the logarithms of the ratios $a_{1} / a_{2}$ and $a_{2} / a_{3}$ are used as ordinate and abscissa. We also defined a degree of anisotropy for the orientation (DA-O), as $\mathrm{DA}-\mathrm{O}=\mathrm{a}_{1} / \mathrm{a}_{3}$. If $\mathrm{DA}-\mathrm{O}=1$, the distribution of the $c$-axis orientation is isotropic.

\section{RESULTS}

\section{Evolution of the snow microstructure}

The evolution of the geometrical microstructure was evaluated using the $\mu \mathrm{CT}$ images (Fig. 1). Temperature gradient metamorphism caused the snow structure to evolve from decomposed and fragmented precipitation particles (DFdc for Group 1 and DFbk for Group 2) to small rounded grains (RGsr) and to large depth hoar (DHcp).

The image of the natural snow block, Group 1, shows the preferentially horizontal arrangement of the snowflakes at week 0 . The snow crystals were mainly platelets and dendrites. Small facets (edges) were observed after the first week, followed by the formation of larger facets and finally large cup crystals. This initial structure was completely dissolved after 4 weeks. The structure after 4 weeks corresponds to solid faceted particles (FCso). Pores grew much larger, and most grains were spaced at least two crystal sizes from each other ( $\mathrm{Sp}_{\mathrm{gr} 1} / \mathrm{Th}_{\mathrm{gr} 1}$ ratio). After 12.5 weeks, well-defined depth hoar had formed with local chain-like structures in the vertical direction. Pores were even larger, and facets could grow unhindered at the bottom side of the structures.

The initial image of the sieved snow block, Group 2, shows no preferential horizontal arrangement of the grains. Pores were smaller than in Group 1. Again, the initial structure completely changed after 4 weeks, but facets were expressed much less than for Group 1, and the individual crystals were more rounded. Well-formed depth hoar (DHcp) developed after 11.5 weeks. In morphology, but not size, the crystals of Groups 1 and 2 were very similar.

The basic structural parameters, density, specific surface area (SSA) and grain and pore thickness, are shown in Figure 2. For Group 1, the density evolved from $178.4 \mathrm{~kg} \mathrm{~m}^{-3}$ at week 0, to $294.8 \mathrm{~kg} \mathrm{~m}^{-3}$ at week 12.5. For Group 2, it evolved from $255.7 \mathrm{~kg} \mathrm{~m}^{-3}$, to $369.1 \mathrm{~kg} \mathrm{~m}^{-3}$ at week 11.5 .

The two snow blocks differed in density by $30 \%$, while the SSA, as well as the thickness of the ice structures, was almost identical. Similarly, density evolved alike, increasing by $\sim 30 \%$ ( $\sim 100 \mathrm{~kg} \mathrm{~m}^{-3}$ within 3 months). SSA decreased more or less linearly by almost $50 \%$, again alike for natural and sieved snow (Group 1: $22.1 \mathrm{~mm}^{-1}$ to $9.3 \mathrm{~mm}^{-1}$; Group 2: $19.9 \mathrm{~mm}^{-1}$ to $9.3 \mathrm{~mm}^{-1}$ ). The pore size of the two samples differed, however, by $\sim 20 \%$. It increased steadily during metamorphism, and was, together with density, the outstanding contrast between the two samples.

\section{Evolution of $\boldsymbol{c}$-axis orientation}

Thin sections, colored with respect to azimuth and colatitude, are shown in Figure 3. The number of crystals decreased about linearly from $\sim 32 \mathrm{~mm}^{-3}$ to $\sim 3 \mathrm{~mm}^{-3}$ for Group 1 samples, and from $\sim 32 \mathrm{~mm}^{-3}$ to $\sim 6 \mathrm{~mm}^{-3}$ for Group 2 samples. The number of crystals in Group 2 increased in the first week due to settlement of the sieved snow. Afterwards, the same decrease in the number of snow crystals was observed as in Group 1 (Table 1). 

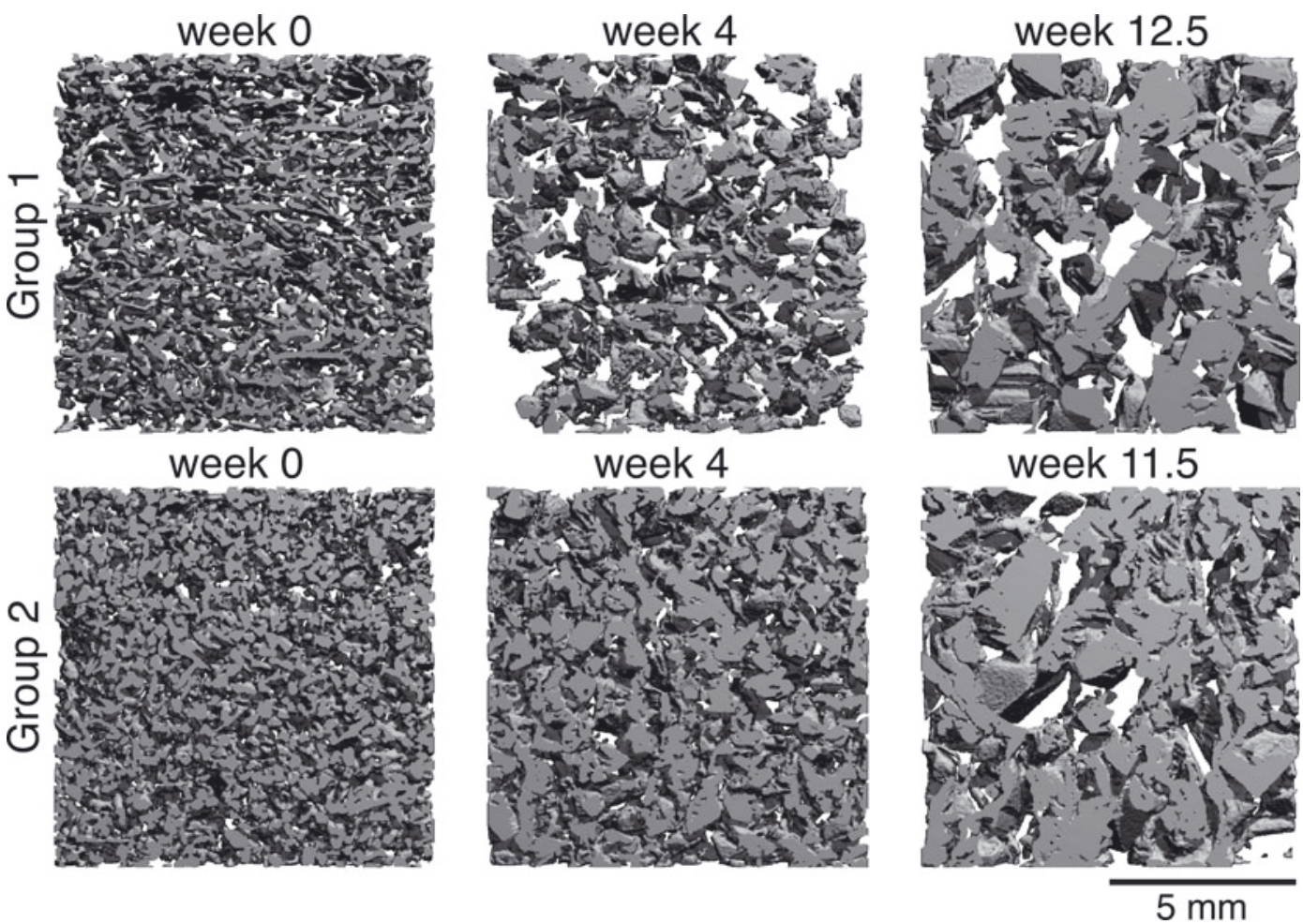

Fig. 1. Evolution of snow structure for both groups at 0,4 and 12.5 (11.5) weeks. The upper row shows Group 1 (natural snow), the lower row Group 2 (sieved snow). The pictures represent a vizualization of 3-D vertical slices of $10 \times 10 \mathrm{~mm}^{2}$ and $0.2 \mathrm{~mm}$ thickness.

The distributions of the $c$-axes for each block at the beginning and end of the experiment are shown in Figures 4 and 5 as Schmidt plots. The initial $c$-axes of the crystals were slightly more vertically oriented (concentrated in the center) for Group 1 than for Group 2. The Schmidt plot for Group 1 between the beginning and end of the experiment showed much more change than for Group 2. Below, we quantify this qualitative information using the eigenvalues of the second-order orientation tensor.

The evolution of the eigenvalues is shown in Figure 6. For Group $1, a_{1}$ decreased continuously while $a_{2}$ increased, toward values typical for a girdle-type fabric. In contrast, in Group 2, $a_{1}, a_{2}$ and $a_{3}$ oscillate slightly around a constant value. For both groups, the $a_{1}$ eigenvalues remain larger than the others throughout the experiment, so the fabric remains anisotropic. These trends were supported by fitting a linear model between time and eigenvalues. The trends were all tested for statistical significance. The $p$-value is the probability that the trend is significantly different from zero. In Group 1, the trends for $a_{1}$ and $a_{2}$ are different from 0 with a

Table 1. Evolution of the number of crystals during the temperature gradient metamorphism experiment

\begin{tabular}{lcc}
\hline $\begin{array}{l}\text { Time } \\
\text { weeks }\end{array}$ & $\begin{array}{c}\text { Group 1 } \\
\text { crystals mm }\end{array}$ & $\begin{array}{c}\text { Group 2 } \\
\text { crystals mm }\end{array}$ \\
\hline 0 & 31.90 & 32.39 \\
1 & 27.18 & 39.31 \\
4 & 11.22 & 27.67 \\
6 & 7.83 & 18.61 \\
11.5 & - & 5.99 \\
12.5 & 2.78 & - \\
& & \\
\hline
\end{tabular}

$p$-value $<0.01$, and for $a_{3}$ with $p<0.1$. The trends for Group 2 were all not different from zero, with $p$-values $>0.5$. The standard deviations for the eigenvalues $\left(a_{1}, a_{2}, a_{3}\right)$ were calculated following Dur and others (2006), by taking into account the effect of the limited number of grains on the estimation of the fabric parameters. This standard deviation is the same for all three eigenvalues, and was therefore only plotted for $a_{1}$ (see error bars in Fig. 6). The higher the number of grains, the lower the standard deviation (e.g. for Group 1, $\sigma_{a_{i}}=0.013$ at week $0\left(N_{a}=927\right)$, and 0.027 at week $\left.12.5\left(N_{a}=171\right)\right)$.

The plot of the ratio between the eigenvalues (Fig. 7) differentiates the evolution between the two groups. According to Woodcock (1977), the ratio $\kappa=\ln \left(a_{1} / a_{2}\right) / \ln \left(a_{2} / a_{3}\right)$ gives objective information about the fabric shape: $\kappa>1$ for single-maximum fabric and $\kappa<1$ for girdle-type fabric. For Group 1, although the fabric concentration remained weak, it evolved from a single-maximum fabric to a girdletype fabric. The strength of the fabric orientation continuously decreased during the experiment. By contrast, the fabric of Group 2 did not evolve, as the variations in fabric are within the range of error from random variations. Note that around week 6, the fabrics of Groups 1 and 2 reached very similar characteristics, and their evolutions differentiated again thereafter.

The degree of anisotropy evolved alike for the structure (DA-S) and orientation (DA-O) for both groups (Fig. 8). Although the magnitudes of DA-S and DA-O differed, the curves are very close when scaled and offset. The magnitude of DA-S was about twice as small as that of DA-O. The structural anisotropy is therefore smaller than the orientation anisotropy. Both measures of anisotropy are initially large for Group 1 samples, and decreased. Note that the fabric did not evolve toward isotropy, but toward a girdle-type fabric, as the eigenvalues $a_{1}$ and $a_{2}$ were getting closer, 
corresponding to an in-plane isotropy. This anisotropy cannot be revealed by the DA-O parameter. The evolution of the DA-O of Group 2 was more scattered, although a slight tendency toward anisotropy seemed to appear, but this was not discernible from random error.

\section{DISCUSSION}

From $\mu \mathrm{CT}$ measurements, we find that the structural evolution of Groups 1 and 2, which differed in density by $30 \%$, is characterized by almost identical absolute and relative decrease in SSA. This shows that the rate of decrease in SSA is not necessarily density-dependent. The structural evolution under the temperature gradient is similar to previous observations (Schneebeli and Sokratov, 2004). The evolution of the structural thickness, Th (Fig. 2), is very similar for both groups within a range of $5 \%$. Their evolution is alike, corresponding to the evolution of SSA. In contrast, pore size, Sp, is $\sim 15 \%$ higher in Group 1 than in Group 2. It increases slightly faster in Group 1 (natural) than in Group 2 (sieved). The rate of densification is, again, very similar for both groups. The increase in density during 12.5 and 11.5 weeks of the experiment is $\sim 30 \%$ for both samples. This is a relatively large increase, considering that the overload pressure at the location of the samples was only $\sim 25 \mathrm{~Pa}$. The settling during the 12.5 weeks was, however, only $15 \%$, and we assume that the increase in density was caused by sublimation of the bottom ice layer and subsequent deposition in the colder zone (Sturm and Benson, 1997), where the samples were extracted.

The grains metamorphosed in the classic sequence, from decomposed particles to faceted crystals and finally to chains of depth hoar. Based on Pinzer and others (2012), we calculated that the crystals underwent at least 11 complete recrystallization cycles. This complete recrystallization explains why a reorientation of the fabric is physically possible.

In the range of density of concern in our samples $(\sim 200$ $400 \mathrm{~kg} \mathrm{~m}^{-3}$ ), the evolution of DA-S was very similar to that in Schneebeli and Sokratov (2004). Lomonaco and others (2011) defined a structural degree of anisotropy which makes it possible to follow a change between vertically and horizontally elongated structure. With their definition, the structure of Group 1 evolves from a very slightly horizontally flattened grain structure to an isotropic one. The structure of Group 2 remains isotropic.

The initial weak, but clear, single-maximum fabric of Group $1\left(a_{1}=0.53\right)$ was also measured by Takahashi and Fujino (1976). This observation contradicts the common assumption (see, e.g., Adams and Miller, 2003) that deposited snow on the ground consists of crystals with random orientation. However, this leaves open the question which kind of initial fabric would be formed by needles and columnar precipitation particles. The initial fabric of Group 2 remained anisotropic $\left(a_{1} \approx 0.48\right)$, only slightly less than for Group 1, but the microstructure was almost isotropic. The shape of the snowflake and the sedimentation could therefore play an important role in the initial texture orientation of the snowpack (Löwe and others, 2007).

The main differences are found in the evolution of the anisotropy parameters, both structural (DA-S) and fabric (DA-O) anisotropy (Fig. 8), and in the eigenvalue ratio (Fig. 7). The initial structural anisotropy is about twice as small as the fabric anisotropy. Therefore we can neglect the impact of a structural change on the fabric evolution from a horizontal

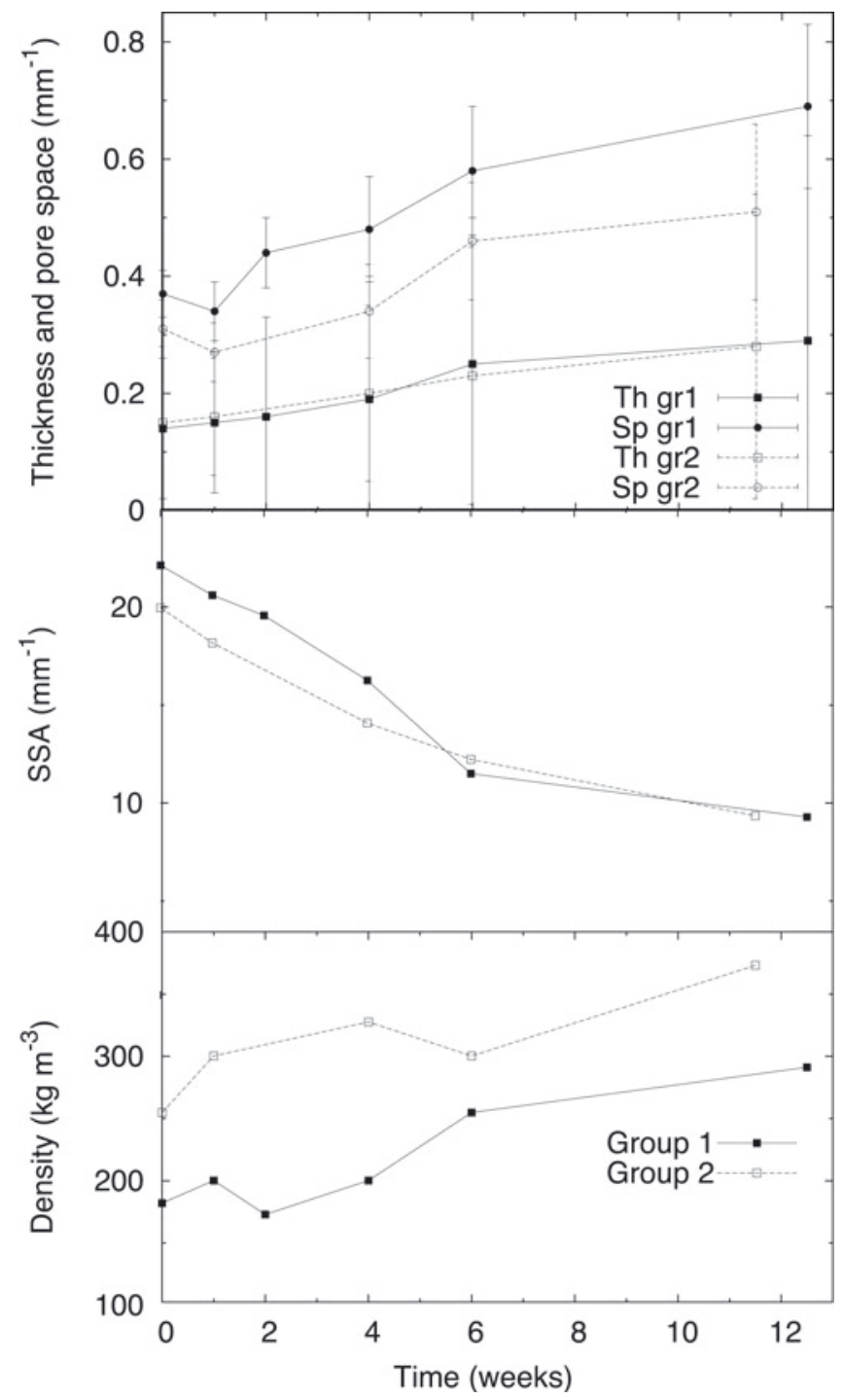

Fig. 2. Evolution of density, specific surface area (SSA), structural thickness (Th) and pore size (Sp) for both groups. The estimated error in the density measurement is close to $10 \%$.

cross section. Indeed, Group 1 (natural snow) clearly shows an evolution from a weak single-maximum fabric with $c$-axes oriented in the vertical direction (perpendicular to the plane of the thin section) toward a transition between single-maximum and girdle-type fabric with $c$-axes oriented close to the horizontal (i.e. the plane of the thin section). In particular, the ratio $a_{1} / a_{2}$ is continuously decreasing, and $a_{2} / a_{3}$ slowly increasing. The fabric in Group 2 (sieved snow) exhibits a more scattered evolution, with little variation in the DA-O and DA-S parameters within the limit of accuracy of the data. Note that both DA-O and DA-S became very similar around week 6 . Nevertheless, a closer observation of the evolution of the eigenvalues (Fig. 7) shows an evolution that DA-O only does not capture clearly. Figure 7 shows that Group 1 evolved from a weak single-maximum fabric towards a weak girdle-type fabric and bypassed Group 2 between weeks 4 and 6 . In contrast, Group 2 remained a weak single-maximum fabric.

The evolution of the fabric toward a weak girdle type, as measured during the temperature gradient metamorphism experiment of Group 1 (natural snow), is very interesting. Indeed, a girdle-type fabric is measured on ice samples growing from the liquid phase under a temperature gradient, 

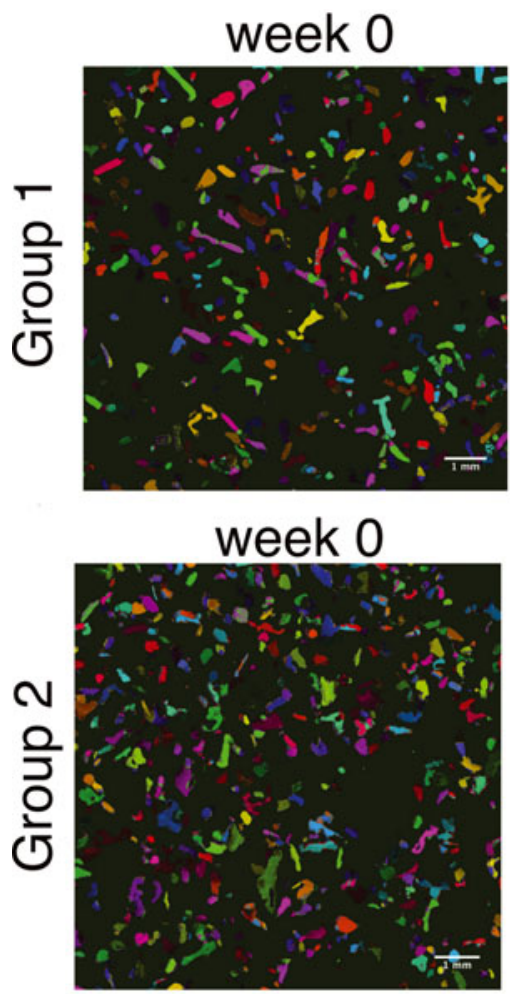
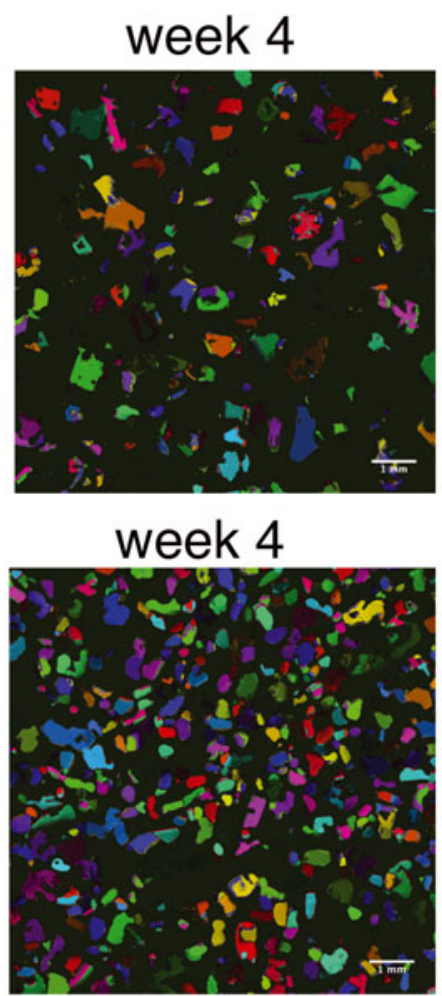

week 12.5

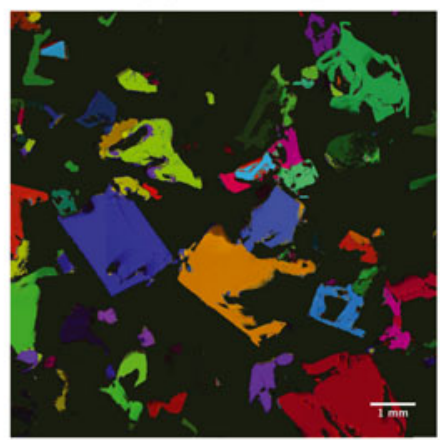

week 11.5

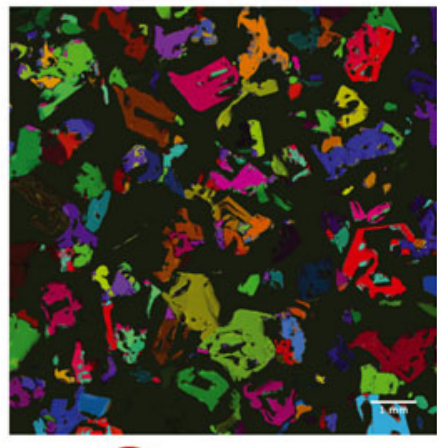

$5 \mathrm{~mm}$

Fig. 3. Horizontal thin sections imaged by the fabric analyzer for Group 1 (natural snow) and Group 2 (sieved snow), with color-coded orientation of the $c$-axis. Hue indicates azimuth, darkness co-latitude. The orientation code is given by the color wheel close to the scale bar.

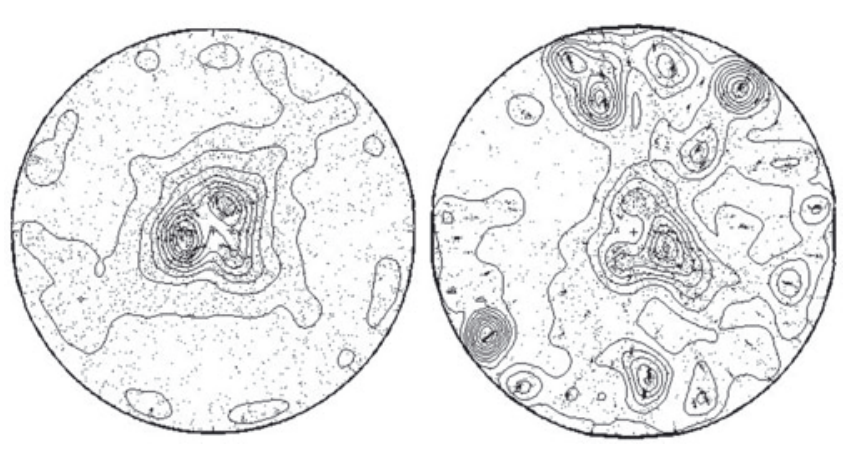

Fig. 4. Schmidt plots for Group $1 c$-axis orientation data, at the beginning (left) and end (right) of the experiment. Each dot is the stereographic projection of the $c$-axis orientation for one pixel of the fabric analyzer raw data.

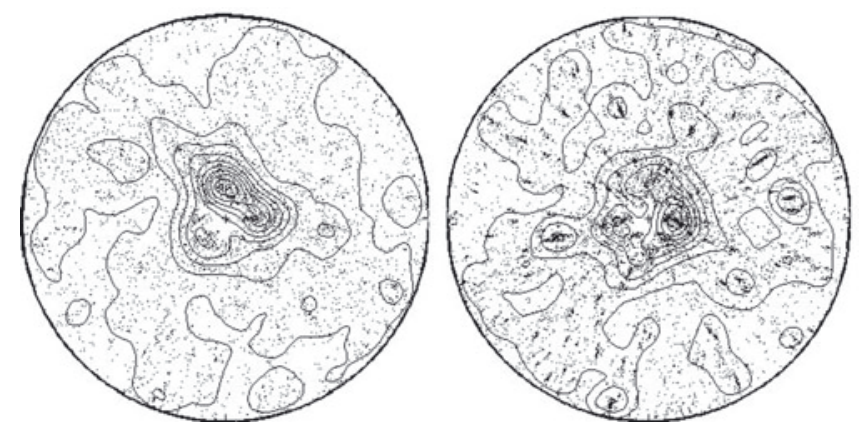

Fig. 5. Schmidt plots for Group $2 \mathrm{c}$-axis orientation at the beginning (left) and end (right) of the experiment. such as columnar S2 ice, with easy growth direction being parallel to the basal planes (Hillig, 1958; Fukuta and Lu, 1994). This observation supports the hypothesis of Miller and Adams (2009) that crystals will grow with a particular crystallographic orientation during temperature gradient metamorphism. This favored orientation growth will strongly depend on temperature and level of supersaturation, and can also be triggered by the configuration of ice structure and pore (Adams and Miller, 2003). A girdle-type fabric coincides with the preferred orientation of single ice crystals at a temperature of $-20^{\circ} \mathrm{C}$ (Kuroda and Lacmann, 1982), as observed here.

Our observations are in qualitative agreement with the hypothesis of Adams and Miller (2003). Furthermore, our experiment shows that the difference in density between two samples (natural snow sample $30 \%$ less dense than sieved snow sample), mainly characterized by differences in pore structure, impacts the efficiency of oriented growth. Marbouty (1980) and Pfeffer and Mrugala (2002) also mention the effect of density on depth-hoar formation.

Our study therefore suggests that fabric evolution during temperature gradient metamorphism is linked to density. Further studies will be needed to quantify this factor more precisely, and in particular the impact of pore size relative to density, as suggested by Adams and Miller (2003).

\section{CONCLUSION}

The evolution of snow texture during temperature gradient metamorphism was observed and analyzed for a natural and a sieved snow sample. Our study demonstrates the ability of the AITA to perform high-resolution fabric measurements in 


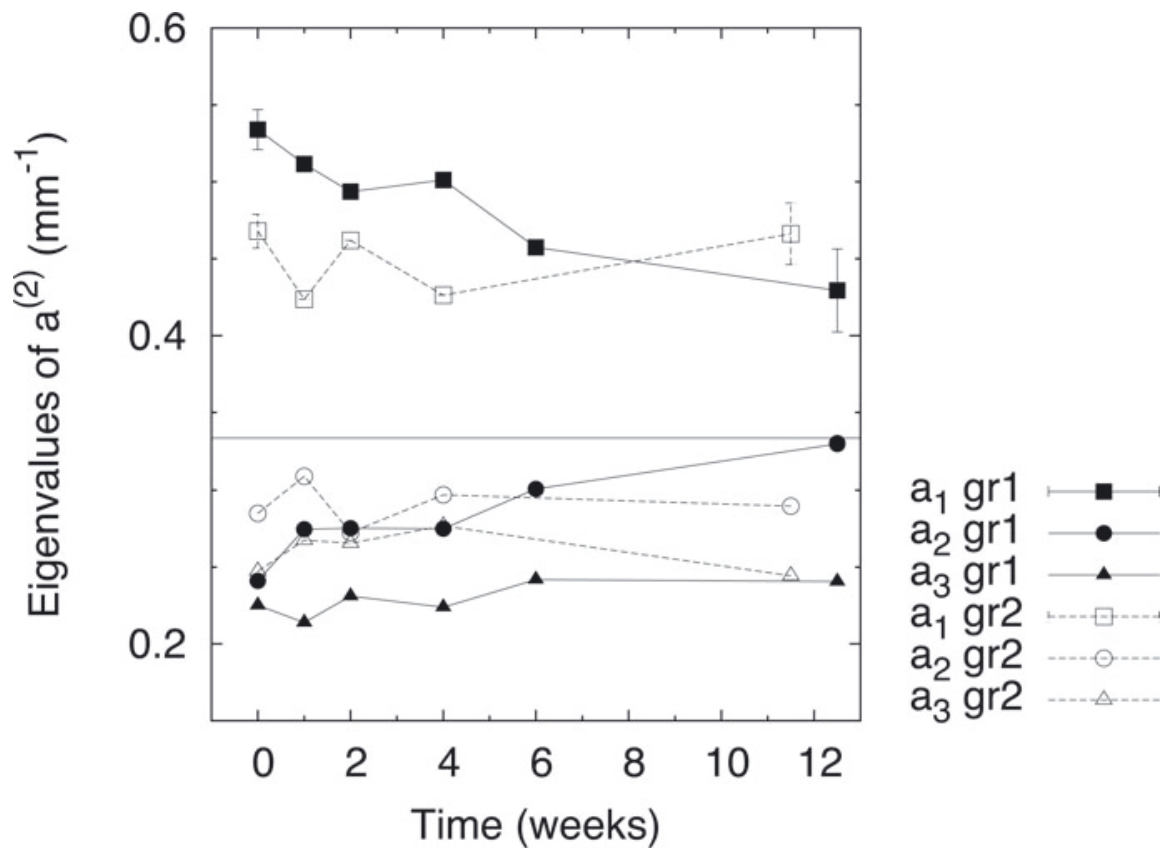

Fig. 6. Evolution of the three eigenvalues of the second-order orientation tensor $\mathbf{a}^{(2)}$ for the two groups (gr1: Group 1; gr2: Group 2). An isotropic fabric would be characterized by three eigenvalues equal to 0.33 (dotted line). Error bars show the standard deviation of the measurements at the beginning and end of the experiment. They are the same for the three eigenvalues.

low-density snow samples. Furthermore, we show complementarity between structural analyses using $\mu \mathrm{CT}$ and fabric characterization. We found that the initial crystal orientation in the snowpack was anisotropic, with a majority of $c$-axes vertically oriented. This anisotropy decreased during the temperature gradient experiment in the natural snow sample characterized by lower density, toward a weak girdle-type fabric with $c$-axes preferentially oriented in the horizontal plane. This evolution was not measured in the denser sample made of sieved snow, although the fabric of both

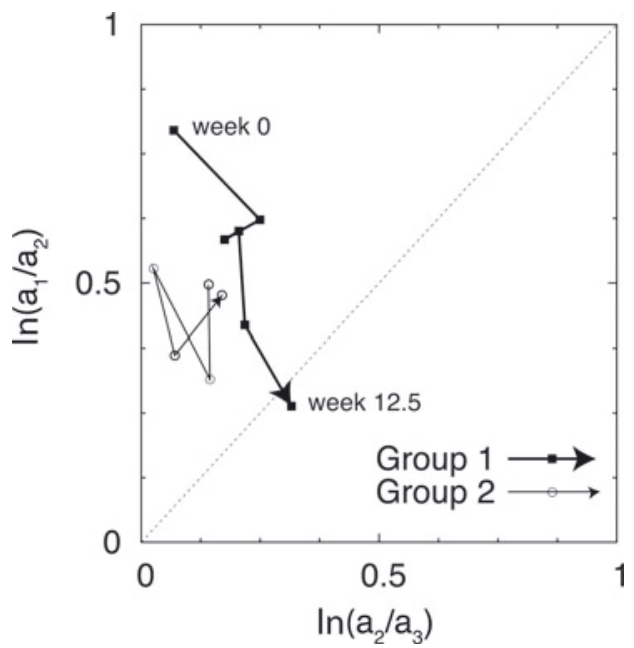

Fig. 7. Evolution of the fabrics of Groups 1 and 2 shown as the natural logarithm of the ratio of eigenvalues. The $x$-axis indicates girdle-type fabric, the $y$-axis single-maximum fabric. Group 1 evolves from a weak single-maximum fabric towards a weak girdletype fabric. Group 2 remains a weak single-maximum fabric. Wellexpressed fabrics have values of $\ln \left(a_{1} / a_{2}\right)$ and $\ln \left(a_{2} / a_{3}\right)$ around 6 (as described in Fisher, 1993, ch. 3). samples became very similar between weeks 4 and 6 . Pore space appeared to have a dominant effect on the fabric evolution. The low-temperature $\left(-20^{\circ} \mathrm{C}\right)$ experiment should be complemented at higher temperatures, as several transitions from preferred basal to prismatic growth are expected between $-2^{\circ} \mathrm{C}$ and $-20^{\circ} \mathrm{C}$ (Kuroda and Lacmann, 1982).

Although more experimental data are necessary to quantify and better understand the interactions between microstructure and fabric evolution during temperature gradient metamorphism, our study demonstrates that the evolution of the fabric could affect the differentiation of snow layers under natural conditions. The complex interaction between metamorphism, the evolution of the microstructure and the evolution of the fabric is still at an early stage of understanding.

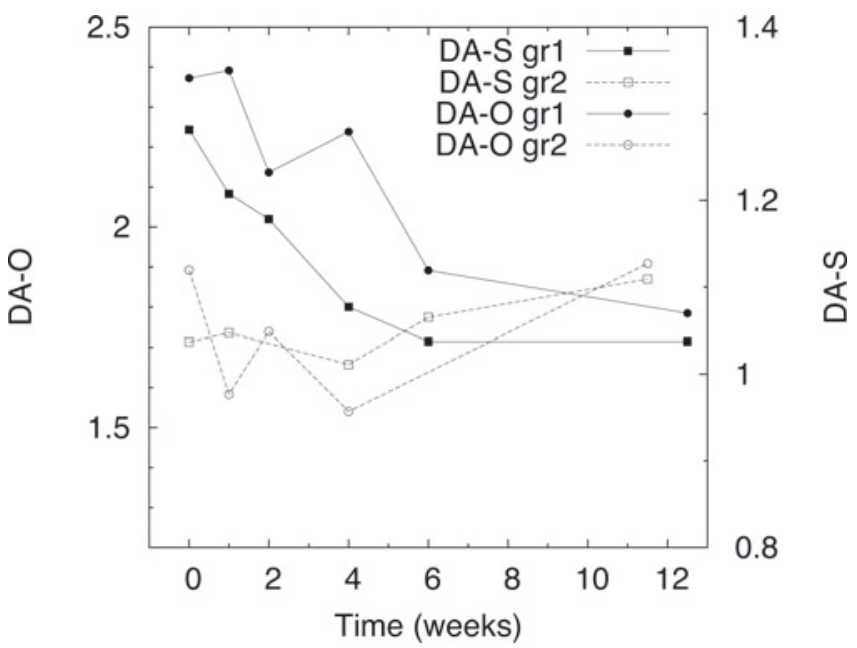

Fig. 8. Comparison of the degree of anisotropy of the structure (DA-S) and of the $c$-axis orientation (DA-O) for the two groups. 


\section{ACKNOWLEDGEMENTS}

This work was funded by the Swiss National Science Foundation (200020_125179), the French CNRS (Centre National de la Recherche Scientifique) institutes INSIS (Institut des Sciences de I'Ingénierie et des Systèmes) and INSU (Institut National des Sciences de I'Univers), and the French National Research Agency (ANR). We acknowledge the European Science Foundation (ESF) for a travel grant (short visit 5185) in the frame of the RNP MicroDlce. We thank N. Calonne, F. Flin and an anonymous reviewer for constructive reviews.

\section{REFERENCES}

Adams EE and Miller DA (2003) Ice crystals grown from vapor onto an orientated substrate: application to snow depth-hoar development and gas inclusions in lake ice. J. Glaciol., 49(164), 8-12 (doi: 10.3189/172756503781830953)

Baddeley A and Vedel Jensen EB (2005) Stereology for statisticians. Chapman and Hall/CRC, Boca Raton, FL (Monographs on Statistics and Applied Probability 103)

Bader H, Haefeli R, Bucher E, Neher J, Eckel O and Thams C (1939) Der Schnee und seine Metamorphose. Beitr. Geol. Schweiz., Geotech. Ser. Hydrol., 3

De Quervain MR (1983) The Institute for Snow and Avalanche Research at Weissfluhjoch/Davos: the first five years (1943 to 1948). Ann. Glaciol., 4, 307-314

Durand G, Gagliardini O, Thorsteinsson T, Svensson A, Kipfstuhl J and Dahl-Jensen D (2006) Ice microstructure and fabric: an upto-date approach for measuring textures. J. Glaciol., 52(179), 619-630 (doi: 10.3189/172756506781828377)

Durand G and 8 others (2007) Change in ice rheology during climate variations - implications for ice flow modelling and dating of the EPICA Dome C core. Climate Past, 3(1), 155-167 (doi: 10.5194/cp-3-155-2007)

Duval P, Ashby MF and Anderman I (1983) Rate-controlling processes in the creep of polycrystalline ice. J. Phys. Chem., 87(21), 4066-4074

Fierz C and 8 others (2009) The international classification for seasonal snow on the ground. UNESCO-International Hydrological Programme, Paris (IHP Technical Documents in Hydrology 83)

Fisher NI (1993) Statistical analysis of circular data. Cambridge University Press, Cambridge

Flin F, Brzoska J-B, Lesaffre B, Coléou C and Pieritz RA (2004) Three-dimensional geometric measurements of snow microstructural evolution under isothermal conditions. Ann. Glaciol., 38, 39-44 (doi: 10.3189/172756404781814942)

Fukuta N and Lu QJ (1994) Surface microphysical mechanism for ice crystal growth habit development. Atmos. Res., 32(1-4), 31-43 (doi: 10.1016/0169-8095(94)90049-3)

Good W (1970) Ein automatisches System zur Aufnahme und Auswertung von kristallinen Dünnschnittpräparaten. Verh. Schweiz. Naturforsch. Ges., 150, 180-187

Heilbronner RP and Pauli C (1993) Integrated spatial and orientation analysis of quartz $C$-axes by computer-aided microscopy. J. Struct. Geol., 15(3-5), 369-382

Hildebrand T and Rüesegger P (1997) A new method for the modelindependent assessment of thickness in three-dimensional images. J. Microsc., 185(1), 67-75 (doi: 10.1046/j.13652818.1997.1340694.x)

Hildebrand T, Laib A, Müller R, Dequeker J and Rüesegger P (1999) Direct 3-D morphometric analysis of human cancellous bone: microstructural data from spine, iliac crest and calcaneus. J. Bone Mineral Res., 14(7), 1167-1174

Hillig WB (1958) The kinetics of freezing of ice in the direction perpendicular to the basal plane. In Doremus RH, Roberts BW and Turnbull D eds. Growth and Perfection of Crystals:
Proceedings of the International Conference on Crystal Growth, 27-29 August 1958, Cooperstown, New York. Wiley, New York, 350-360

Hörhold MW, Kipfstuhl S, Wilhelms F, Freitag J and Frenzel A (2011) The densification of layered polar firn. J. Geophys. Res., 116(F1), F01001 (doi: 10.1029/2009JF001630)

Kaempfer TU, Schneebeli M and Sokratov SA (2005) A microstructural approach to model heat transfer in snow. Geophys. Res. Lett., 32(21), L21503 (doi: 10.1029/2005GL023873)

Kuroda T and Lacmann R (1982) Growth kinetics of ice from the vapour phase and its growth forms. J. Cryst. Growth, 56(1), 189-205 (doi: 10.1016/0022-0248(82)90028-8)

Lomonaco R, Albert MR and Baker I (2011) Microstructural evolution of fine-grained layers through the firn column at Summit, Greenland. J. Glaciol., 57(204), 755-762 (doi: 10.3189/002214311797409730)

Löwe H, Egli L, Bartlett S, Guala M and Manes C (2007) On the evolution of the snow surface during snowfall. Geophys. Res. Lett., 34(21), L21507 (doi: 10.1029/2007GL031637)

Ludwig W and 7 others (2009) Three-dimensional grain mapping by x-ray diffraction contrast tomography and the use of Friedel pairs in diffraction data analysis. Rev. Sci. Instr., 80(3), 033905 (doi: 10.1063/1.3100200)

Magono C and Suzuki S (1967) A study on crystal axes of snow crystals with complicated shapes, utilizing a polarization microscope. J. Fac. Sci., Hokkaido Univ., 3(1), 27-35

Marbouty D (1980) An experimental study of temperature-gradient metamorphism. J. Glaciol., 26(94), 303-312

Miller DA and Adams EE (2009) A microstructural dry-snow metamorphism model for kinetic crystal growth. J. Glaciol., 55(194), 1003-1011 (doi: 10.3189/002214309790794832)

Montagnat $M$ and 6 others (2012) Measurements and numerical simulation of fabric evolution along the Talos Dome ice core, Antarctica. Earth Planet. Sci. Lett., 357-358, 168-178 (doi: 10.1016/j.epsl.2012.09.025)

Nelson J (2001) Growth mechanisms to explain the primary and secondary habits of snow crystals. Philos. Mag. A, 81(10), 2337-2373 (doi: 10.1080/01418610108217152)

Peternell M, Kohlmann F, Wilson CJL, Seiler C and Gleadow AJW (2009) A new approach to crystallographic orientation measurement for apatite fission track analysis: effects of crystal morphology and implications for automation. Chem. Geol., 265(3-4), 527-539 (doi: 10.1016/j.chemgeo.2009.05.021)

Pfeffer WT and Mrugala R (2002) Temperature gradient and initial snow density as controlling factors in the formation and structure of hard depth hoar. J. Glaciol., 48(163), 485-494 (doi: 10.3189/172756502781831098)

Pinzer BR and Schneebeli M (2009) Snow metamorphism under alternating temperature gradients: morphology and recrystallization in surface snow. Geophys. Res. Lett., 36(23), L23503 (doi: 10.1029/2009GL039618)

Pinzer BR, Schneebeli M and Kaempfer TU (2012) Vapor flux and recrystallization during dry snow metamorphism under a steady temperature gradient as observed by time-lapse micro-tomography. Cryosphere, 6(5), 1141-1155 (doi: 10.5194/tc-6-11412012)

Riche F and Schneebeli M (2010) Microstructural change around a needle probe to measure thermal conductivity of snow. J. Glaciol., 56(199), 871-876 (doi: 10.3189/ 002214310794457164)

Riche F, Schneebeli M and Tschanz SA (2012) Design-based stereology to quantify structural properties of artificial and natural snow using thin sections. Cold Reg. Sci. Technol., 79-80, 67-74 (doi: 10.1016/j.coldregions.2012.03.008)

Rigsby GP (1951) Crystal fabric studies on Emmons Glacier, Mount Rainier, Washington. J. Geol., 59(6), 590-598

Rolland du Roscoat S and 6 others (2011) Analysis of snow microstructure by means of x-ray diffraction contrast tomography. Adv. Eng. Mater., 13(3), 128-135 (doi: 10.1002/ adem.201000221) 
Schneebeli M and Sokratov SA (2004) Tomography of temperature gradient metamorphism of snow and associated changes in heat conductivity. Hydrol. Process., 18(18), 3655-3665 (doi: 10.1002/hyp.5800)

Stephenson PJ and Lister H (1959) Preliminary results of the glaciological work on the Trans-Antarctic Expedition, 1955-58. J. Glaciol., 3(25), 426-431

Sturm M and Benson CS (1997) Vapor transport, grain growth and depth-hoar development in the subarctic snow. J. Glaciol., 43(143), 42-59

Takahashi Y and Fujino K (1976) Crystal orientation of fabrics in a snow pack. Low Temp. Sci., Ser. A 34, 71-78

Theile T, Löwe H, Theile TC and Schneebeli M (2011) Simulating creep of snow based on microstructure and the anisotropic deformation of ice. Acta Mater., 59(18), 7104-7113 (doi: 10.1016/j.actamat.2011.07.065)

Thorsteinsson T, Kipfstuhl J and Miller H (1997) Textures and fabrics in the GRIP ice core. J. Geophys. Res., 102(C12), 26 583-26599

Wilson CJL, Russell-Head DS and Sim HM (2003) The application of an automated fabric analyzer system to the textural evolution of folded ice layers in shear zones. Ann. Glaciol., 37, 7-17 (doi: $10.3189 / 172756403781815401)$

Wilson CJL, Russell-Head DS, Kunzi K and Viola G (2007) The analysis of quartz c-axis fabrics using a modified optical microscope. J. Microsc., 227(1), 30-41 (doi: 10.1111/j.13652818.2007.01784.x)

Woodcock NH (1977) Specification of fabric shapes using an eigenvalue method. Geol. Soc. Am. Bull., 88(9), 1231-1236

MS received 29 June 2012 and accepted in revised form 12 October 2012 